\title{
Removal of Beta-Lactams Antibiotics through Zero-Valent Copper Nanoparticles
}

\author{
Lucas M. F. Oliveira, ${ }^{a}$ Mayra A. Nascimento, ${ }^{a}$ Yuri M. Guimarães, ${ }^{a}$ André F. Oliveira, ${ }^{a}$ \\ Antônio A. Silva ${ }^{b}$ and Renata P. Lopes* $* a$ \\ ${ }^{a}$ Departamento de Química, Universidade Federal de Viçosa, 36570-000 Viçosa-MG, Brazil \\ ${ }^{b}$ Departamento de Fitotecnia, Universidade Federal de Viçosa, 36570-000 Viçosa-MG, Brazil
}

\begin{abstract}
The removal of the beta-lactam antibiotics (ceftriaxone and cefadroxil) through zero-valent copper nanoparticle (nZVC) was studied in this work. Excellent removal degrees $(>85 \%)$ were obtained for both analytes in only 20 min of reaction. Studies were performed in both oxic and anoxic conditions, and in the presence of $t$-butyl alcohol (TBA), an inhibitor of radicals. The results did not show significant changes. Therefore, the hydroxyl radicals are not the main species responsible for the removal. Total organic carbon cefadroxil analysis indicated a removal of 57\% after 180 min of reaction. Studies involving $\mathrm{Cu}^{+}$indicated that probably these are the principal species responsible for the removal of antibiotics. Kinetic studies have shown that two-phase reaction occurred in the antibiotics removal process and both phases followed pseudo-first order kinetic model. The first mechanism is related to the antibiotics degradation by $\mathrm{Cu}^{+}$species and the second mechanism is related to the antibiotics adsorption by hydroxides/oxides of $\mathrm{Cu}^{2+}$ species.
\end{abstract}

Keywords: zero-valent copper, nanoparticles, beta-lactams, removal

\section{Introduction}

The cephalosporin antibiotics are $\beta$-lactams that act by inhibiting the peptidoglycan synthesis of bacterial cell wall. ${ }^{1}$ These drugs are widely used in the world, due to the treatment from moderate to severe infections and for patients allergic to penicillin. ${ }^{2}$ Ceftriaxone and cefadroxil are representatives of cephalosporin family that inhibit bacterial synthesis. Cefadroxil is an antibiotic used for the treatment of various urinary tract infections, skin and soft tissues as well as pharyngitis and tonsillitis. ${ }^{3}$ Ceftriaxone has a broad antibacterial spectrum including Gram-positive and specially Gram-negative bacteria. ${ }^{4}$

High levels of orally administered dosages of these compounds are excreted unchanged in urine. ${ }^{3}$ Thus, the presence of these compounds in the domestic sewage can contaminate water bodies. As a result, studies detected the presence of antibiotics in surface waters. ${ }^{5-8}$ Once in the environment, antibiotics can cause various biological effects on non-target organisms, such as genotoxicity in aquatic organisms. ${ }^{9}$ Moreover, expression of antibiotics residues may develop resistance to these compounds in certain microorganisms, some of them pathogenic for humans. ${ }^{9}$

*e-mail: renata.plopes@ufv.br
Although conventional biological treatment processes of wastewater are effective in removing some antibiotics, some of these compounds, such as beta-lactams, sulfonamides, trimethoprim, macrolides, fluoroquinolones and tetracyclines, were found in concentrations of 10$1000 \mathrm{ng} \mathrm{\textrm {L } ^ { - 1 }}$ in secondary treated effluents. ${ }^{1}$ Therefore, it is necessary to develop new processes able to degrade these compounds.

In this sense, the use of zero-valent metals such as iron, copper, nickel, and zinc has played a significant role in the degradation process of organic pollutants in wastewater, such as antibiotics. ${ }^{10,11}$ The nanometric metals are more reactive and have high reactivity due to the very high surface area to weight ratio, resulting in higher reactivity rates than micron scale metals. ${ }^{12}$

Among the metals used, zero-valent copper (ZVC) has been shown to be effective in removing different contaminants, such as diethyl phthalate, ${ }^{11}$ azo contaminants, ${ }^{13}$ carbon tetrachloride, ${ }^{14,15}$ dichloromethane, ${ }^{16}$ methyl orange, ${ }^{17}$ phenol, ${ }^{18}$ mono chloroaromatics, ${ }^{19}$ and methylene blue. ${ }^{20}$

$\mathrm{ZVC}$ is able to promote the reduction of $\mathrm{O}_{2}$ to $\mathrm{H}_{2} \mathrm{O}_{2}$, this being a thermodynamically favorable process because the standard potential of copper is equal to $\mathrm{Cu}^{+} / \mathrm{Cu}$ $\left(\mathrm{E}^{0}=0.522 \mathrm{~V}\right)$ and $\mathrm{Cu}^{2+} / \mathrm{Cu}\left(\mathrm{E}^{0}=0.341 \mathrm{~V}\right)$, that are more negative than that of $\mathrm{O}_{2} / \mathrm{H}_{2} \mathrm{O}_{2}(0.695 \mathrm{~V}) .{ }^{13}$ Once present in the system, zero-valent copper nanoparticle (nZVC) can 
be oxidized forming $\mathrm{Cu}^{\mathrm{I}}$ and $\mathrm{Cu}^{\mathrm{II}}$ (equations 1 and 2). ${ }^{13}$

$2 \mathrm{Cu}+\mathrm{O}_{2}+2 \mathrm{H}_{2} \mathrm{O} \rightarrow 2 \mathrm{Cu}^{+}+\mathrm{H}_{2} \mathrm{O}_{2}+2 \mathrm{OH}^{-}$

$\mathrm{Cu}+\mathrm{O}_{2}+2 \mathrm{H}_{2} \mathrm{O} \rightarrow \mathrm{Cu}^{2+}+\mathrm{H}_{2} \mathrm{O}_{2}+2 \mathrm{OH}^{-}$

Hydroxyl radical $(\bullet \mathrm{OH})$ may be produced through decomposition of hydrogen peroxide $\left(\mathrm{H}_{2} \mathrm{O}_{2}\right)$ by $\mathrm{Cu}^{+}$via the Fenton reaction (equation 3 ) whereas superoxide radicals can be formed by $\mathrm{H}_{2} \mathrm{O}_{2}$ decomposition catalyzed by $\mathrm{Cu}^{2+}$ (equation 4$).{ }^{13}$

$\mathrm{Cu}^{+}+\mathrm{H}^{+}+\mathrm{H}_{2} \mathrm{O}_{2} \rightarrow \mathrm{Cu}^{2+}+\bullet \mathrm{OH}+\mathrm{H}_{2} \mathrm{O}$

$\mathrm{Cu}^{2+}+\mathrm{H}_{2} \mathrm{O}_{2} \rightarrow \mathrm{Cu}^{+}+\bullet \mathrm{O}_{2}^{-}+2 \mathrm{H}^{+}$

Copper is a mild hydrogenation catalyst ${ }^{16,21}$ and was used to promote the contaminants dehalogenation such as dichloromethane ${ }^{16}$ and chloroaromatic compounds ${ }^{19}$ in the presence of sodium borohydride. In addition, $\mathrm{ZVC}$ is a good electron donor ${ }^{17}$ and can participate in degradation processes via electrochemical reactions. ZVC can also induce Sandmeyer's reaction. According to Dong et al. ${ }^{13}$ the azo bonding break of the dye occurred via the Sandmeyer reaction, since the $\mathrm{nZVC}$ could activate molecular oxygen producing $\mathrm{H}_{2} \mathrm{O}_{2}$ and releasing $\mathrm{Cu}^{\mathrm{I}}$ for the system of carbon center radicals.

Thus, this work aimed at studying the removal of cefadroxil and ceftriaxone in aqueous systems mediated by nZVC. A series of experiments were proposed to investigate the mechanism of antibiotic removal by nZVC and to investigate an influence of factors such as nanomaterial dosage, initial concentration, temperature and $\mathrm{pH}$ in the kinetics of antibiotic removal.

\section{Experimental}

\section{Chemicals}

All chemicals used were of analytical grade. Sodium borohydride (minimum 98.0\%), $t$-butyl alcohol (TBA), acetonitrile (high performance liquid chromatography (HPLC) grade), phosphoric acid (40 wt. $\% \mathrm{H}_{3} \mathrm{PO}_{4}$ ), cefadroxil ( $>98 \%$ ) and ceftriaxone ( $>98 \%$ ) were purchased from Sigma-Aldrich. Copper sulfate pentahydrate, ethanol and sulfuric acid $(\geq 98 \%)$ were purchased from Vetec. All aqueous solutions were prepared using purified water from a Milli-Q system and they were stored at $4{ }^{\circ} \mathrm{C}$.

\section{nZVC synthesis}

The nZVC were prepared with adjustments to the methodology reported by Raut et al. ${ }^{19}$ The mass of
$\mathrm{CuSO}_{4} .5 \mathrm{H}_{2} \mathrm{O}(8.846 \mathrm{~g})$ was transferred to $100 \mathrm{~mL}$ of ethanol-water mixture $(4: 1, \mathrm{v} / \mathrm{v})\left(0.354 \mathrm{~mol} \mathrm{~L}^{-1}\right)$ and the system was stirred for $20 \mathrm{~min}$. After stirring, sodium borohydride solution $\left(1.080 \mathrm{~mol} \mathrm{~L}^{-1}\right)$ was added dropwise to the mixture at a rate of about 2 drops per second with constant stirring, for about $1 \mathrm{~h}$. After metal reduction, the copper nanoparticles were filtered, washed with water and ethanol and then stored in freezer (at $-20{ }^{\circ} \mathrm{C}$ ). The characterization of the $\mathrm{nZVC}$ was performed using a transmission electron microscope (TEM; Tecnai G2-20 and SuperTwin FEI) equipped with a microanalysis system for $\mathrm{X}$-ray energy dispersive spectroscopy (EDS).

\section{Beta-lactams removal experiments}

The beta-lactams removal assays were performed in a glass cylindrical reactor of $200 \mathrm{~mL}$ coated by a water jacket connected with temperature control, under oxic (open system) or anoxic conditions (closed system). Nitrogen was used for anoxic conditions. The mass of ZVC was added to the system containing ceftriaxone or cefadroxil solution. The system was maintained under constant agitation using a mechanical stirrer. Reaction aliquots were removed at different time intervals ( $1 \mathrm{~min}$ for ceftriaxone and $50 \mathrm{~s}$ for cefadroxil), filtered (cellulose membrane $0.47 \mu \mathrm{m}$, Millipore) and analyzed by HPLC. Kinetic studies were also conducted, evaluating the influence of different antibiotic concentrations $\left(0.050-0.18 \mathrm{mmol} \mathrm{L}^{-1}\right.$ for ceftriaxone and $0.14-0.28 \mathrm{mmol} \mathrm{L}^{-1}$ for cefadroxil), system temperatures $\left(10-40^{\circ} \mathrm{C}\right.$ for ceftriaxone and $5-35^{\circ} \mathrm{C}$ for cefadroxil), nanoparticle dosages $\left(0.50-1.50 \mathrm{~g} \mathrm{~L}^{-1}\right.$ for ceftriaxone and $0.50-2.00 \mathrm{~g} \mathrm{~L}^{-1}$ for cefadroxil) and initial $\mathrm{pH}$ (3.70-8.80 for cefadroxil) of the system.

The removal kinetics of the antibiotics was modeled using a pseudo-first-order rate equation (equation 5):

$\ln \frac{\mathrm{C}}{\mathrm{C}_{0}}=-\mathrm{k}_{\mathrm{obs}} \mathrm{t}$

where $\mathrm{C}$ is the antibiotics concentration at reaction time $\mathrm{t}$; $\mathrm{C}_{0}$ is the initial concentration of antibiotic; and $\mathrm{k}_{\mathrm{obs}}$ is apparent kinetic rate constant of pseudo first-order kinetics.

All assays were performed in replicate and the uncertainty in the final concentration of the solution was less than $5 \%$.

\section{Analytical procedures}

The characterization of the nanoparticles was performed using a SuperTwin FEI TEM, equipped with a microanalysis system for EDS. 
The antibiotics removal was monitored through HPLC (Shimadzu, LC 20AT) with a UV-Vis detector (Shimadzu SPD 20A) using a C18 column (Shimadzu VP-ODS Shim-pack $150 \times 4.6 \mathrm{~mm}^{2}$ i.d.). The following operational conditions were employed: isocratic elution of acetonitrile:0.1\% phosphoric acid solution (20:80 v/v); a

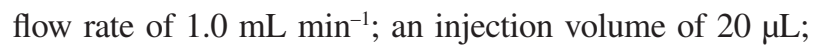
and the UV-Vis detector set at 258 and $228 \mathrm{~nm}$ wavelengths for ceftriaxone and cefadroxil, respectively. The remaining ceftriaxone and cefadroxil were identified by comparing the retention times of the standard with the samples, and the concentrations were estimated using the analytical curves (0.0090-0.36 mmol L-1 for ceftriaxone (coefficient of determination $\left.\left(\mathrm{R}^{2}\right)=0.9989\right)$ and $0.014-0.41 \mathrm{mmol} \mathrm{L}^{-1}$ for cefadroxil $\left(\mathrm{R}^{2}=0.9988\right)$ ). The dissolved organic carbon (DOC) was determined by a DOC analyzer (Shimadzu, $5000 \mathrm{~A}$ ), at a temperature of $380^{\circ} \mathrm{C}$ and using platinum as the catalyst after filtration of the samples (membrane $0.47 \mu \mathrm{m}$ ).

\section{Results and Discussion}

\section{Characterization of nZVC}

The nanoparticles were smaller than $50 \mathrm{~nm}$ and they form agglomerates, as can be observed in the TEM images (Figure 1). The nanometric size gives the nanoparticles a greater ratio between the surface area and the volume of the material, which gives higher reactivity due to the greater number of active sites for reaction. ${ }^{22}$ The agglomerates formed may be present due to magnetic interactions between the metal nanoparticles. ${ }^{23,24}$ One of the causes of small particulate formation is the excess of sodium borohydride used in its preparation, which promotes a rapid reduction of the metal. ${ }^{25}$ Other researchers have also obtained copper nanoparticles with a similar diameter, for example, Huang et al. ${ }^{16}$ produced nanoparticles with an average diameter of $50 \mathrm{~nm}$, whereas Dong et al. ${ }^{13}$ produced nanoparticles with $30 \mathrm{~nm}$.

The EDS spectrum of the nZVC shows that copper is the main element present in the composition of the nanomaterials. Other elements are also present such as $\mathrm{S}$, $\mathrm{O}$ and $\mathrm{C}$. The sulfur and oxygen presence was caused by $\mathrm{CuSO}_{4} .5 \mathrm{H}_{2} \mathrm{O}$ residues used for nanomaterials preparation. The carbon was from the support in which the sample was inserted.

\section{Antibiotics removal by $\mathrm{nZVC}$}

The removal of the ceftriaxone and the cefadroxil by nZVC at oxic conditions, can be observed in Figure 2. As it can be seen, the removal degrees in only $20 \mathrm{~min}$ of reaction were approximately $97 \%$ (ceftriaxone) and $85 \%$ (cefadroxil), demonstrating that nZVC was highly efficient to remove antibiotics. Note that the antibiotics concentration remained constant throughout the control experiment, i.e., in the absence of nZVC.

In order to verify if the compounds mineralization occurs, the dissolved organic carbon (DOC) was monitored over time for cefadroxil removal reaction by $\mathrm{nZVC}$ (Figure 3).

The DOC analysis for cefadroxil shows a reduction of ca. $15 \%$ organic carbon in 20 min of reaction by $\mathrm{nZVC}$ in oxic conditions. This result indicates that a partial DOC reduction occurs because a decrease of $85 \%$ of the cefadroxil chromatographic peak in the same time interval was observed. This result is an indication that the cefadroxil removal does not occur by adsorption, or occurs at reduced rates, since the molecule is adhered to nanoparticles in the adsorption process. However, it should be noted that over time the DOC is reduced, reaching a reduction of ca. $57 \%$ of organic carbon after $180 \mathrm{~min}$, indicating that the degradation products were removed.
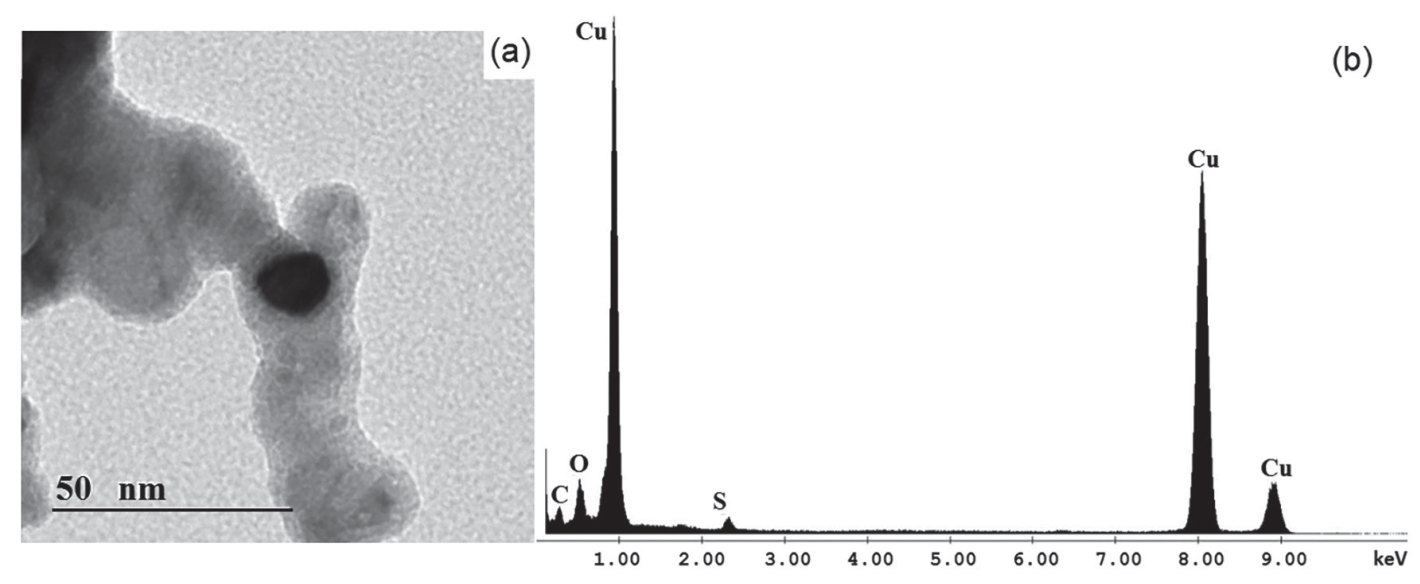

Figure 1. (a) TEM image of nZVC; (b) EDS of nZVC. 

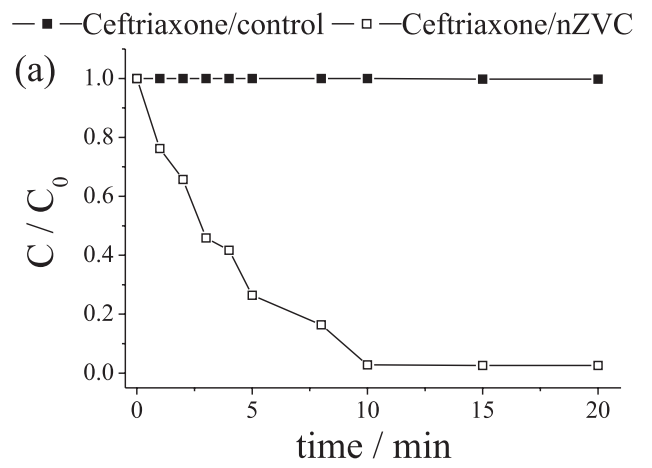

- Cefadroxil/control $\multimap$ Cefadroxil/nZVC

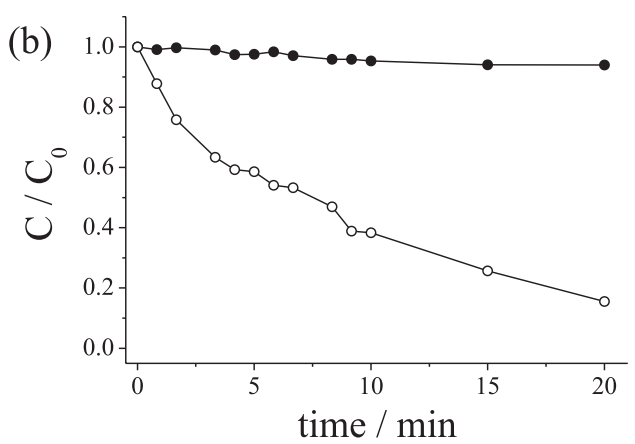

Figure 2. (a) Ceftriaxone removal and (b) cefadroxil removal by nZVC. Experimental conditions: $\mathrm{C}_{0 \text { ceftriaxone }}=0.090 \mathrm{mmol} \mathrm{L}^{-1}$ and $\mathrm{C}_{\text {0cefadroxil }}=0.21 \mathrm{mmol} \mathrm{L}^{-1}$; solution volume $=100 \mathrm{~mL} ; \mathrm{nZVC}$ dosage $=1.0 \mathrm{~g} \mathrm{~L}^{-1}$, reaction time $=20 \mathrm{~min}$; temperature $=25.0^{\circ} \mathrm{C}$. The coefficient of variation between the replicates was lower than $5 \%$.

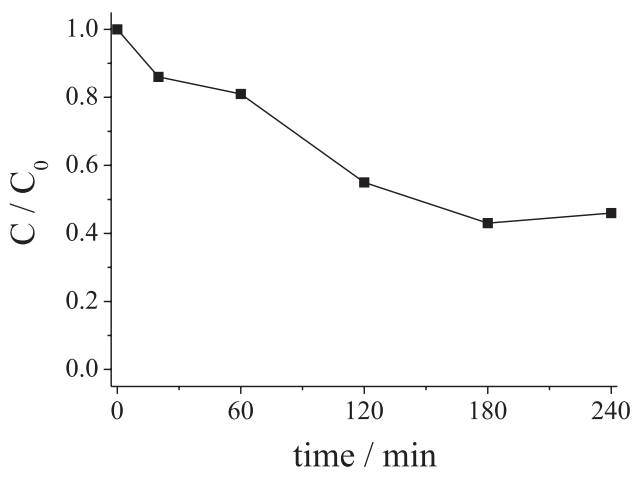

Figure 3. DOC results for cefadroxil removal by nZVC under oxic system. Experimental conditions: $\mathrm{C}_{\text {0cefadroxil }}=0.21 \mathrm{mmol} \mathrm{L}^{-1}$; solution volume $=100 \mathrm{~mL}$; $\mathrm{nZVC}$ dosage $=1.0 \mathrm{~g} \mathrm{~L}^{-1}$; reaction time $=10 \mathrm{~min}$; temperature $=25.0^{\circ} \mathrm{C}$. The coefficient of variation between the replicates was lower than $5 \%$.

Study of the species responsible for the removal of antibiotics by $\mathrm{nZVC}$

Since the adsorption process is not in principle responsible for antibiotics removal by nZVC, additional experiments were performed to determine which species are responsible for the degradation.

Studies indicate that ZVC can produce various reactive species in the system that can promote the removal of ceftriaxone and cefadroxil. Some of these species are hydroxyl radicals $(\bullet \mathrm{OH})$ and superoxide $\left(\cdot \mathrm{O}_{2}^{-}\right)$, which can be formed during the decomposition of hydrogen peroxide, whose formation is described in equations 3 and $4 .{ }^{13}$ To verify the contribution of these radicals in the antibiotics removal, experiments were performed under anoxic (bubbling $\mathrm{N}_{2}$ ) and oxic conditions and in the presence of TBA under oxic conditions (Figure 4), since TBA acts as an $\bullet \mathrm{OH}$ radical inhibitor.

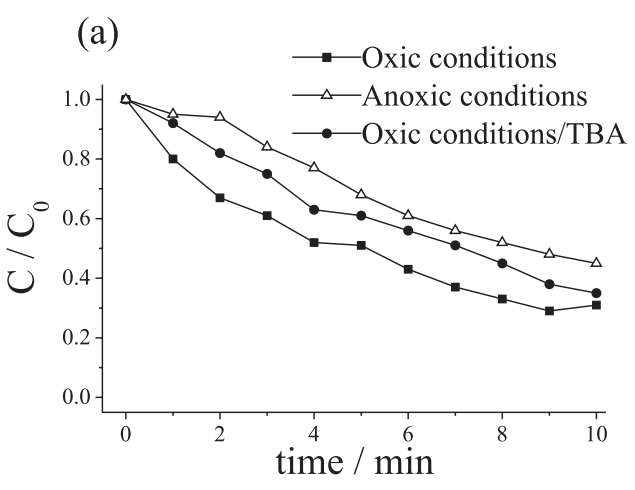

(b)

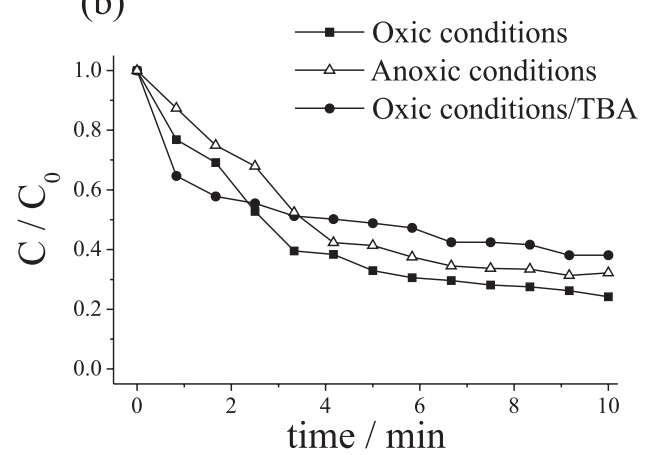

Figure 4. Removal of ceftriaxone (a) and cefadroxil (B) by nZVC in anoxic or oxic system and with or without TBA addition under oxic system. Experimental conditions: $\mathrm{C}_{\text {0ceftriaxone }}=0.090 \mathrm{mmol} \mathrm{L}-1$ and $\mathrm{C}_{0 \text { cefadroxil }}=0.21 \mathrm{mmol} \mathrm{L}^{-1}$; solution volume $=100 \mathrm{~mL} ; \mathrm{nZVC}$ dosage $=1.0 \mathrm{~g} \mathrm{~L}^{-1} ;$ TBA dosage $=1.0 \mathrm{mmol} \mathrm{L}^{-1}$; reaction time $=10 \mathrm{~min}$; temperature $=25.0^{\circ} \mathrm{C}$. The coefficient of variation between the replicates was lower than $5 \%$.

As can be seen in Figure 4, the presence of TBA promotes slight inhibition of the reaction, since ceftriaxone removal degree was about 65 to $69 \%$ in the presence and absence of TBA, respectively, while for cefadroxil it was about 62 and $76 \%$, respectively. These results indicate that, although hydroxyl radicals can be formed, they are not the main species responsible for degradation. According to equation 3 , the hydroxyl radicals $(\bullet \mathrm{OH})$ are formed under acid conditions. However, in this system, antibiotic reactions occurs in basic media ( $\mathrm{pH}$ ca. 9.5), which does not favor the formation of $\bullet \mathrm{OH}$. Wen et al..$^{21}$ observed that the TBA inhibited the diethyl phthalate degradation, however, at acid medium ( $\mathrm{pH} 2.5)$. 
The cefadroxil removal degrees in oxic and anoxic conditions were, respectively, 68 and $76 \%$ at 10 min reaction, while for ceftriaxone it was about 54 and $69 \%$, respectively, which demonstrate that oxygen has a small participation in the removal process, since the elimination of dissolved oxygen slightly inhibited the removal of antibiotics. These results confirm our initial hypothesis that hydroxyl radicals are not the main species to act in the drugs removal. Possibly, the redox processes involving copper are very important, thus, in order to check the contribution of the species of $\mathrm{Cu}^{+}$in the antibiotic removal, an assay was conducted using copper oxide $\left(\mathrm{Cu}_{2} \mathrm{O}\right)$ in the removal of cefadroxil (Figure 5).

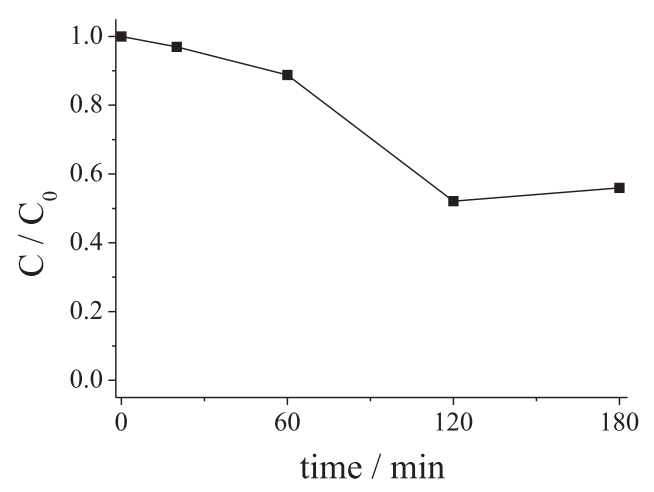

Figure 5. Cefadroxil removal by $\mathrm{Cu}_{2} \mathrm{O}$. Experimental conditions: $\mathrm{C}_{\text {ocefarroxil }}=0.21 \mathrm{mmol} \mathrm{L}^{-1}$; solution volume $=100 \mathrm{~mL} ;$ Cu dosage $=1.0 \mathrm{~g} \mathrm{~L}^{-1}$; $\mathrm{Cu}_{2} \mathrm{O}$ dosage $=1.1 \mathrm{~g} \mathrm{~L}^{-1}$; reaction time $=180 \mathrm{~min}$; temperature $=25.0^{\circ} \mathrm{C}$. The coefficient of variation between the replicates was lower than $5 \%$.

As shown in Figure 5, the cefadroxil removal rate was about $50 \%$ at $120 \mathrm{~min}$ of reaction. Although the removal kinetics is different compared to $\mathrm{nZVC}$, it can be seen that possibly the species of $\mathrm{Cu}^{+}$are very important in the removal process. The difference between antibiotics removal rate by $\mathrm{Cu}_{2} \mathrm{O}$ compared to $\mathrm{Cu}$ nanoparticles can be attributed to the fact that the nZVC have a larger contact surface due to their nanometric size. Moreover, the nZVC are spread more evenly in system, favoring the mass transport between the nanoparticles and the substrate. Therefore, the reaction by nZVC occurs more rapidly compared with the reaction by $\mathrm{Cu}_{2} \mathrm{O}$. Finally, it can be concluded that $\mathrm{Cu}^{+}$is one of the most important species in the removal of the compound. It is noteworthy that experiments were conducted using $\mathrm{Cu}^{2+}$ under the same conditions. However, cefadroxil removal was not satisfactory. This phenomenon demonstrates that $\mathrm{Cu}^{2+}$ is not involved in the cefadroxil removal process.

\section{Kinetic studies}

\section{Effect of antibiotic concentration}

Different concentrations of antibiotics (0.050$0.18 \mathrm{mmol} \mathrm{L}^{-1}$ for ceftriaxone and $0.14-0.28 \mathrm{mmol} \mathrm{L}^{-1}$ for cefadroxil) were studied in a fixed dosage of nZVC $\left(1 \mathrm{~g} \mathrm{~L}^{-1}\right)$ as can be seen in Figure 6.
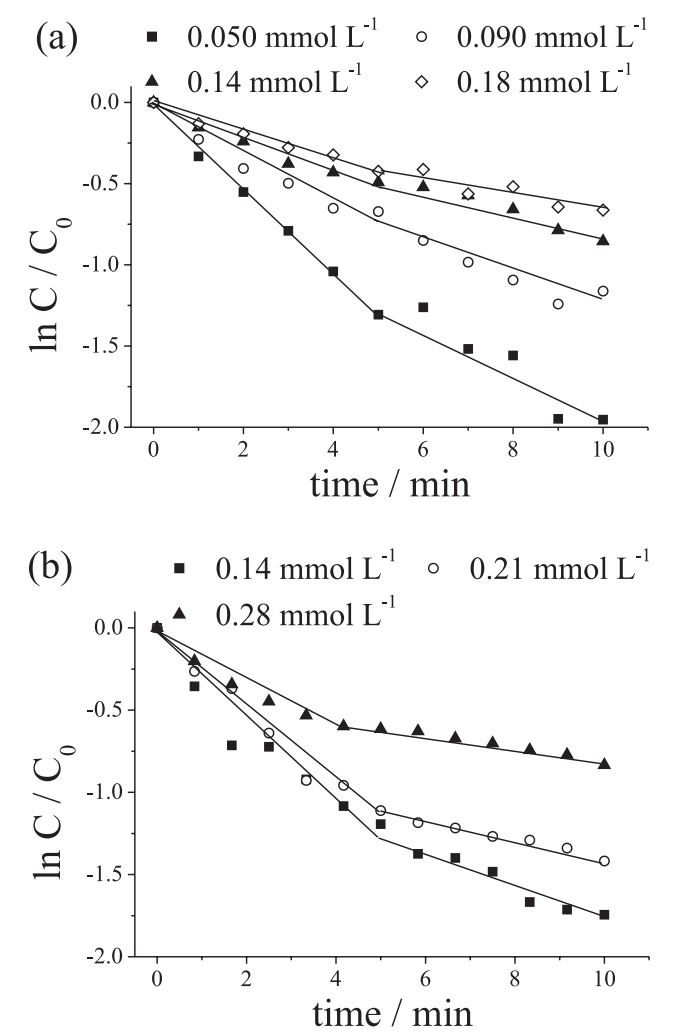

Figure 6. Kinetic effect of initial antibiotic concentration on removal efficiency of (a) ceftriaxone and (b) cefadroxil. Experimental conditions: solution volume $=100 \mathrm{~mL}$; $\mathrm{nZVC}$ dosage $=1.0 \mathrm{~g} \mathrm{~L}^{-1}$; reaction time $=10 \mathrm{~min}$; temperature $=25.0^{\circ} \mathrm{C}$. The coefficient of variation between the replicates was lower than $5 \%$.

As observed in Figure 6, the removal of both antibiotics followed a pseudo-first order kinetic model with a change in reaction mechanism, an event that can be observed due to a change in slope of the lines at approximately $5 \mathrm{~min}$. It is believed that the first reaction mechanism ( 0 to $5 \mathrm{~min}$ ) is due to $\mathrm{Cu}^{+}$species and the second mechanism can be attributed to the antibiotics adsorption process that occurs on the nanoparticles surface (Figure 7).

The cefadroxil removal rate was approximately 66 and $76 \%$ for a concentration of $0.21 \mathrm{mmol} \mathrm{L}^{-1}$ at 5 (when the

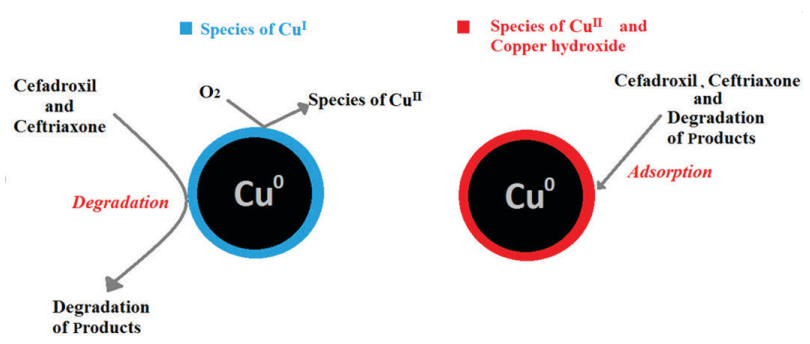

Figure 7. Schematic representation of the cefadroxil and ceftriaxone removal by copper nanoparticles. 
mechanism changed) and $10 \mathrm{~min}$, respectively (Figure 6b). It is noteworthy that DOC assays showed a total organic carbon removal of only $15 \%$ after 20 min of reaction (Figure 3). It is believed that the DOC removal occurs due to the adsorption process, since it has been previously proven that oxidative processes are not primarily responsible for the removal of antibiotics. As the $\mathrm{Cu}^{+}$species react rapidly with the drugs and can be rapidly oxidized to $\mathrm{Cu}^{2+}$ by oxygen, ${ }^{21}$ the second mechanism could be due to the antibiotics adsorption of copper hydroxides/oxides that could be formed and be passivating the nanoparticles surface. Arfaoui et al. ${ }^{26}$ synthesized $\mathrm{CuO}$ nanorods to promote the adsorption of $\mathrm{Pb}^{\mathrm{II}}$, showing that copper(II) oxides have adsorbent properties.

Figure 6 shows that the removal rate of the antibiotics decreased as initial concentrations increased, at the monitored reaction time, for both compounds. For ceftriaxone (increasing the initial concentration from 0.050 to $0.18 \mathrm{mmol} \mathrm{L}^{-1}$ ), the kinetic constant of removal $\left(\mathrm{k}_{\mathrm{obs}}\right)$ for the first mechanism (phase 1) decreased from 0.264 to $0.087 \mathrm{~min}^{-1}$, while that for the second mechanism (phase 2) decreased from 0.153 to $0.053 \mathrm{~min}^{-1}$. For cefadroxil (increasing the initial concentration from 0.14 to $0.28 \mathrm{mmol} \mathrm{L}^{-1}$ ) the $\mathrm{k}_{\text {obs }}$ decreased from 0.267 to $0.160 \mathrm{~min}^{-1}$ for phase 1 , while for phase 2 it decreased from 0.111 to $0.040 \mathrm{~min}^{-1}$.

\section{Effect of temperature}

The effect of reaction temperature on the effectiveness of the removal was studied increasing the reaction temperature from 283.2 to $313.2 \mathrm{~K}$ for ceftriaxone and from 278.2 to $308.2 \mathrm{~K}$ for cefadroxil. As observed in the concentration effect of both antibiotics, the reaction also followed with a mechanism change. The increase in the temperature of the system causes an increase in reaction rate, which can be evidenced by the rate constants for both mechanisms as shown in Tables 1 and 2.

\section{Effect of nanoparticle dosages}

The effect of nZVC dosages variation $\left(0.500-2.00 \mathrm{~g} \mathrm{~L}^{-1}\right.$ for cefadroxil and $0.500-1.50 \mathrm{~g} \mathrm{~L}^{-1}$ for ceftriaxone) on the antibiotics removal was investigated. Figure 8 shows the normalized constants, i.e., $\mathrm{k}_{\mathrm{obs}} / \mathrm{C}_{0} v s . \mathrm{nZVC}$ dosage. The normalization is important to compare the results of both compounds. As it can be seen, the removal efficiency increases as the nZVC dosage increased for both antibiotics. Similarly, the removal follows with a mechanism change.

The nZVC dosage increase causes an increase in reaction rate. The $\mathrm{k}_{\mathrm{obs}} / \mathrm{C}_{0}$ for ceftriaxone, at a dosage of $0.500 \mathrm{~g} \mathrm{~L}^{-1}$, were 0.497 and $0.729 \mathrm{~L} \mathrm{~min}^{-1} \mathrm{mmol}^{-1}$ for the first and second phases, respectively, whereas for
Table 1. Rate constant $\left(\mathrm{k}_{\mathrm{obs}}\right)$ for ceftriaxone removal at different temperatures. Experimental conditions: solution volume $=100 \mathrm{~mL} ; \mathrm{nZVC}$ dosage $=1.0 \mathrm{~g} \mathrm{~L}^{-1} ; \mathrm{C}_{\text {0ceftriaxone }}=0.09 \mathrm{mmol} \mathrm{L}^{-1}$. The coefficient of variation between the replicates was lower than $5 \%$

\begin{tabular}{lccccc}
\hline \multirow{2}{*}{ Temperature / $\mathrm{K}$} & \multicolumn{2}{c}{$\mathrm{k}_{\mathrm{obs}} / \mathrm{min}^{-1}$} & & \multicolumn{2}{c}{$\mathrm{R}^{2}$} \\
\cline { 2 - 3 } \cline { 5 - 6 } & Phase 1 & Phase 2 & & Phase 1 & Phase 2 \\
\hline 283.2 & 0.030 & 0.027 & & 0.998 & 0.989 \\
293.2 & 0.098 & 0.13 & & 0.993 & 0.968 \\
303.2 & 0.13 & 0.20 & & 0.994 & 0.989 \\
313.2 & 0.22 & 0.22 & & 0.992 & 0.993 \\
\hline
\end{tabular}

$\mathrm{k}_{\mathrm{obs}}$ : rate constant; $\mathrm{R}^{2}$ : coefficient of determination.

Table 2. Rate constant $\left(\mathrm{k}_{\mathrm{obs}}\right)$ for cefadroxil removal at different temperatures. Experimental conditions: solution volume $=100 \mathrm{~mL} ; \mathrm{nZVC}$ dosage $=1.0 \mathrm{~g} \mathrm{~L}^{-1} ; \mathrm{C}_{\text {0cefadroxil }}=0.21 \mathrm{mmol} \mathrm{L}^{-1}$. The coefficient of variation between the replicates was lower than $5 \%$

\begin{tabular}{lccccc}
\hline \multirow{2}{*}{ Temperature / $\mathrm{K}$} & \multicolumn{2}{c}{$\mathrm{k}_{\mathrm{obs}} / \mathrm{min}^{-1}$} & & \multicolumn{2}{c}{$\mathrm{R}^{2}$} \\
\cline { 2 - 3 } \cline { 5 - 6 } & Phase 1 & Phase 2 & & Phase 1 & Phase 2 \\
\hline 278.2 & 0.034 & 0.054 & & 0.996 & 0.928 \\
288.2 & 0.046 & 0.052 & & 0.959 & 0.974 \\
298.2 & 0.15 & 0.033 & & 0.977 & 0.938 \\
308.2 & 0.25 & 0.14 & & 0.971 & 0.973 \\
\hline
\end{tabular}

$\mathrm{k}_{\mathrm{obs}}:$ rate constant; $\mathrm{R}^{2}$ : coefficient of determination.

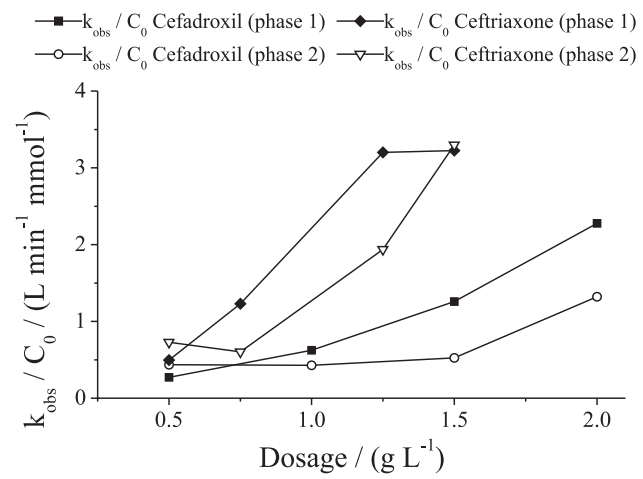

Figure 8. Kinetic effect of nZVC dosages on removal efficiency. Experimental conditions: $\mathrm{C}_{\text {0ceftriaxone }}=0.090 \mathrm{mmol} \mathrm{L} \mathrm{L}^{-1}$ and $\mathrm{C}_{\text {0cefadroxil }}=0.21 \mathrm{mmol} \mathrm{L}^{-1}$; solution volume $=100 \mathrm{~mL}$; reaction time $=10 \mathrm{~min}$; temperature $=25.0^{\circ} \mathrm{C}$. The coefficient of variation between the replicates was lower than $5 \%$.

$1.50 \mathrm{~g} \mathrm{~L}^{-1}$, the $\mathrm{k}_{\text {obs }} / \mathrm{C}_{0}$ were 3.22 and $3.30 \mathrm{~L} \mathrm{~min}^{-1} \mathrm{mmol}^{-1}$ for the first and second phases, respectively. For cefadroxil at a dosage of $0.500 \mathrm{~g} \mathrm{~L}^{-1}$, the $\mathrm{k}_{\text {obs }} / \mathrm{C}_{0}$ were 0.271 and $0.437 \mathrm{~L} \mathrm{~min}^{-1} \mathrm{mmol}^{-1}$ for the first and second phases, respectively, whereas for $2.00 \mathrm{~g} \mathrm{~L}^{-1}$, the $\mathrm{k}_{\text {obs }} / \mathrm{C}_{0}$ were 2.28 and $1.32 \mathrm{~L} \mathrm{~min}^{-1} \mathrm{mmol}^{-1}$ for the first and second phases, respectively.

The ceftriaxone removal increased from 39 (nZVC dosage $\left.=0.500 \mathrm{~g} \mathrm{~L}^{-1}\right)$ to $90 \%\left(\right.$ nZVC dosage $\left.=1.50 \mathrm{~g} \mathrm{~L}^{-1}\right)$ 
at $10 \mathrm{~min}$ of reaction, whereas cefadroxil removal increased from 51 (nZVC dosage $\left.=0.500 \mathrm{~g} \mathrm{~L}^{-1}\right)$ to ca. $100 \%(\mathrm{nZVC}$ dosage $\left.=1.50 \mathrm{~g} \mathrm{~L}^{-1}\right)$ in the same reaction time. This phenomenon occurs due to the increase in reactive species in the system that promotes the antibiotics removal, mainly $\mathrm{Cu}^{+}$species.

Wen et al..$^{21}$ observed that an increase in the ZVC dosage leads to an increase of diethyl phthalate removal rate. These researchers attribute this phenomenon to an increase in the production of $\mathrm{Cu}^{\mathrm{I}}$ and $\mathrm{H}_{2} \mathrm{O}_{2}$, which leads to an increase in removal rate of the compound.

\section{Effect of $\mathrm{pH}$}

The normalized constants, i.e., $\mathrm{k}_{\text {obs }} / \mathrm{C}_{0} v s$. initial $\mathrm{pH}$ of the cefadroxil system, can be observed in Figure 9. As it can be seen, the rate constant increases with the initial $\mathrm{pH}$ of the system. For example, the $\mathrm{k}_{\text {obs }} / \mathrm{C}_{0}$ at $\mathrm{pH} 3.0$ were 0.0070 and $0.0030 \mathrm{~L} \mathrm{~min}^{-1} \mathrm{mmol}^{-1}$ for the first and second phases, respectively, whereas for $\mathrm{pH} 9.0$, the $\mathrm{k}_{\mathrm{obs}} / \mathrm{C}_{0}$ were 0.020 and $0.0090 \mathrm{~L} \mathrm{~min}^{-1} \mathrm{mmol}^{-1}$ for the first and second phases, respectively.

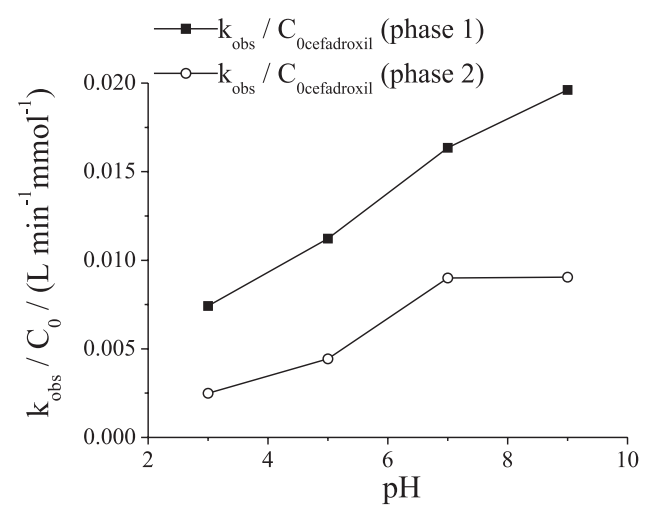

Figure 9. Kinetic effect of $\mathrm{pH}$ on antibiotics removal efficiency of cefadroxil by nZVC. Experimental conditions: $\mathrm{C}_{\text {0cefadroxil }}=0.21 \mathrm{mmol} \mathrm{L}^{-1}$; solution volume $=100 \mathrm{~mL} ; \mathrm{nZVC}$ dosage $=1.0 \mathrm{~g} \mathrm{~L}^{-1}$; reaction time $=10 \mathrm{~min}$; temperature $=25^{\circ} \mathrm{C}$. The coefficient of variation between the replicates was lower than $5 \%$.

Although the system $\mathrm{pH}$ is suddenly increased in few seconds of reaction (ca. 9.5 in only $30 \mathrm{~s}$ ), as shown in the Supplementary Information (SI) section (Figure S1), it can be seen that the initial $\mathrm{pH}$ of the system affects the removal rate. This $\mathrm{pH}$ increase can be attributed to oxidation of ZVC which releases $\mathrm{OH}^{-}$ions in the system (equations 1 and 2). The lowest $\mathrm{pH}$ variation along the reaction is observed for the system whose initial $\mathrm{pH}$ of the solution was 9.0 $(\Delta \mathrm{pH}=0.10)$. As can be seen in Figure 9, both removal phases were affected with $\mathrm{pH}$ increase, but the first phase was more pronounced. Thus, it can be concluded that the main species responsible for antibiotics removal are formed at the beginning of the reaction.

\section{Conclusions}

In this work, the removal of beta-lactam antibiotics through nZVC was studied. Excellent removal rates in a few minutes of reaction were obtained, showing that these processes are very promising in the decontamination of these compounds in aqueous systems. Experiments were also conducted in oxic and anoxic conditions, and in the presence of $t$-butyl alcohol, which is an inhibitor of hydroxyl radicals. These studies indicate that although they may be formed, hydroxyl radicals are not the principal species responsible for the removal of the compounds. In this regard, studies were conducted using $\mathrm{Cu}^{+}$to verify that these species could be acting in removal of the compounds. The results indicate that $\mathrm{Cu}^{+}$are possibly the main species involved in the removal of the compounds studied. It has been found that the removal follows a pseudo first model order with changing mechanism. The first mechanism is due to $\mathrm{Cu}^{+}$species that promote a degradation of the antibiotics and the second mechanism is due to copper hydroxides/oxides that promote the antibiotics adsorption. The rate constants increased as the system temperature, $\mathrm{pH}$, and nanoparticles dosages increased and as the initial concentration of the drugs decreased.

\section{Supplementary Information}

Supplementary information is available free of charge at http://jbcs.sbq.org.br as PDF file.

\section{Acknowledgments}

The authors thank the financial support from CNPq/FAPEMIG (agreement recorded in SICONV: 793988/2013), FAPEMIG, CAPES and CNPq (National Council for Scientific and Technology Development, process 449909/2014-0). We also thank the Center of Microscopy at the Universidade Federal de Minas Gerais (http://www.microscopia.ufmg.br) for providing the equipment and technical support for experiments involving electron microscopy.

\section{References}

1. Le-Minh, N.; Khan, S. J.; Drewes, J. E.; Stuetz, R. M.; Water Res. 2010, 44, 4295.

2. Campagna, J. D.; Bond, M. C.; Schabelman, E.; Hayes, B. D.; J. Emerg. Med. 2012, 42, 612.

3. Hu, Y.; Smith, D. E.; Biochem. Pharmacol. 2016, 107, 81.

4. De Diego Glaría, M.; Moscciati, G. G.; Ramos, R. G.; Riquelme, M. M.; J. Sep. Sci. 2003, 26, 939. 
5. Feitosa-Felizzola, J.; Chiron, S.; J. Hydrol. 2009, 364, 50.

6. Watkinson, A. J.; Murby, E. J.; Kolpin, D. W.; Costanzo, S. D.; Sci. Total Environ. 2009, 407, 2711.

7. Tamtam, F.; Mercier, F.; Bot, B. L.; Eurin, J.; Dinh, Q. T.; Clément, M.; Chevreuil, M.; Sci. Total Environ. 2008, 393, 84.

8. Zhang, X.; Li, Y.; Liu, B.; Wang, J.; Feng, C.; Gao, M.; Wang, L.; PLoS One 2014, 9, 1.

9. Durán-Álvarez, J. C.; Avella, E.; Ramírez-Zamora, R. M.; Zanella, R.; Catal. Today 2016, 266, 175.

10. Ghauch, A.; Tuqan, A.; Assi, H. A.; Environ. Pollut. 2009, 157, 1626.

11. Weng, X.; Sun, Q.; Lin, S.; Chen, Z.; Megharaj, M.; Naidu, R.; Chemosphere 2014, 103, 80.

12. Carroll, D.; Sleep, B.; Krol, M.; Boparai, H.; Kocur, C.; Adv. Water Resour. 2013, 51, 104.

13. Dong, G.; Ai, Z.; Zhang, L.; Water Res. 2014, 66, 22.

14. Lin, C. J.; Lo, S.; Liou, Y. H.; Chemosphere 2005, 59, 1299.

15. Liou, Y. H.; Lo, S. L.; Lin, C. J.; Water Res. 2007, 41, 1705.

16. Huang, C.-C.; Lo, S.-L.; Lien, H.-L.; Chem. Eng. J. 2012, 203, 95.

17. Li, P.; Song, Y.; Wang, S.; Tao, Z.; Yu, S.; Liu, Y.; Ultrason. Sonochem. 2015, 22, 132.
18. Chand, R.; Ince, N. H.; Gogate, P. R.; Bremner, D. H.; Sep. Purif. Technol. 2009, 67, 103.

19. Raut, S. S.; Kamble, S. P.; Kulkarni, P. S.; Chemosphere 2016 , $159,359$.

20. Mekewi, M. A.; Darwish, A. S.; Amin, M. S.; Eshaq, G.; Bourazan, H. A.; Egypt. J. Pet. 2016, 25, 269.

21. Wen, G.; Wang, S. J.; Ma, J.; Huang, T. L.; Liu, Z. Q.; Zhao, L.; Xu, J. L.; J. Hazard. Mater. 2014, 275, 193.

22. Liu, W. J.; Qian, T. T.; Jiang, H.; Chem. Eng. J. 2014, 236, 448.

23. Chang, C.; Lian, F.; Zhu, L.; Environ. Pollut. 2011, 159, 2507.

24. Fang, Z.; Qiu, X.; Chen, J.; Qiu, X.; J. Hazard. Mater. 2011, 185, 958.

25. Bokare, A. D.; Chikate, R. C.; Rode, C. V.; Paknikar, K. M.; Environ. Sci. Technol. 2007, 41, 7437.

26. Arfaoui, L.; Kouass, S.; Dhaouadi, H.; Jebali, R.; Touati F.; Mater. Res. Bull. 2015, 70, 284.

Submitted: September 4, 2017 Published online: February 27, 2018 